\title{
Transobturator tape for female stress incontinence: follow-up after 24 months
}

\author{
Waleed Al Taweel, MD, FRCSC; Danny M. Rabah MD, FRCSC, FACS
}

\section{Abstract}

Objective: The objective of this paper is to evaluate the effectiveness of transobturator vaginal tape (TOT) in the treatment of female stress urinary incontinence (SUI) and to analyze functional results and quality of life after 24 months follow-up.

Methods: The study included all women with SUI who underwent a TOT procedure in which the sling passes from the obturator foramen from the outside to the inside, under general or regional anesthesia from December 2004 to January 2006. All study patients must have had a minimal follow-up of 24 months. The patients were prospectively evaluated, and the following factors were assessed: number of pads used per day, physical examination including pelvic examination, urinalysis, urogenital distress inventory (UDI-6), analog global satisfaction scale (GSS), pad weight test, and urodynamic studies including filling cystometry and Valsalva leak point pressure (VLPP) test.

Results: Fifty-two consecutive patients who fulfilled the inclusion criteria underwent TOT procedure by 1 surgeon. The mean age was $50 \pm 9$ (range 37-72) and minimal follow-up was 24 months (range 24-30 months). Two patients were lost to follow-up after 12 months and 3 patients did not come for the 24-month evaluation. The mean operative time was 18 minutes \pm 4 (range 15-31), with an average amount of bleeding $57 \mathrm{cc} \pm 22 \mathrm{cc}$. Our results demonstrate a $92 \%$ cure or improvement rate after 12 months, and an $85 \%$ after 24 months.

Conclusion: The transobturator approach from outside to inside is a very effective treatment of SUI with low morbidity. However, longer follow-up in larger populations should assess the longterm reliability of this procedure.

Can Urol Assoc J 2010;4(1):33-6

\section{Résumé}

Objectif : L'objectif de notre étude est d'évaluer l'efficacité de la bandelette transobturatrice mise en place par voie vaginale dans le traitement de l'incontinence urinaire d'effort (IUE) et d'analyser les résultats fonctionnels et la qualité de vie après un suivi de 24 mois. Méthodologie : Notre étude a inclus toutes les femmes atteintes $d^{\prime} I U E$ chez qui on avait posé une bandelette transobturatrice passant par le trou obturateur de l'extérieur vers l'intérieur, sous anesthésie générale ou régionale entre décembre 2004 et janvier 2006. Toutes les patientes devaient avoir été suivies pendant un minimum de 24 mois après l'intervention. Les patientes étaient évaluées de façon prospective, et les facteurs suivants ont été évalués : nombre de culottes de protection contre les fuites urinaires utilisées chaque jour, examen physique comprenant un examen pelvien, analyse d'urines, questionnaire UDI-6 (urogenital distress inventory), échelle analogique de satisfaction globale, test du poids de la culotte de protection, et études urodynamiques comprenant une cystométrie de remplissage et une évaluation du seuil de pression de fuite de Valsalva (méthode VLPP).

Résulfats : Cinquante-deux patientes consécutives répondant aux critères $d^{\prime}$ 'inclusion se sont vu poser une bandelette transobturatrice par le même chirurgien. L'âge moyen était de 50 ans \pm 9 (de 37 à 72 ans) et le suivi minimal était de 24 mois (de 24 à 30 mois). Deux patientes avaient été perdues de vue lors du suivi après 12 mois et 3 patientes ne se sont pas présentées à l'évaluation au $24^{\mathrm{e}}$ mois. La durée moyenne de l'intervention était de 18 minutes \pm 4 (de 15 à 31 minutes), et la quantité moyenne de sang perdu de $57 \mathrm{~mL} \pm 22$. Nos résultats montrent un taux de guérison ou d'amélioration de $92 \%$ après 12 mois, et de $85 \%$ après 24 mois. Conclusion : La technique de la bandelette transobturatrice posée de l'extérieur vers l'intérieur est un traitement très efficace de I'IUE accompagnée d'un faible taux de morbidité. Cependant, un suivi plus long avec des cohortes plus importantes est requis pour évaluer la fiabilité à long terme de cette intervention.

\section{Introduction}

Stress urinary incontinence (SUI) is defined as involuntary urine leakage on effort or exertion (e.g., on sneezing or coughing) without rise in detrusor pressure. ${ }^{1}$ The surgical treatment of female SUI, due to urethral hypermobility, changed radically a few years ago when Ulmsten and Petros described a new concept of mid-urethral support without tension. ${ }^{2}$ The mid-urethral sling provides continence by creating functional kinking of the mid-urethra during increased intra-abdominal pressure and the associated rotational descent of the bladder neck and proximal urethra. Karram and colleagues ${ }^{3}$ found that tension-free vaginal tape (TVT) is a safe and successful procedure, but serious though rare complications have been reported with this technique, including vascular and bowel injuries related to the passage of the sling through the retropubic space. ${ }^{4.5}$

In 2001, Delorme described a new method of inserting the tape, which passes through the obturator foramen. ${ }^{6}$ 
The transobturator approach (TOT) for sub-urethral tensionfree vaginal tapes has since gained wide popularity in the surgical treatment of SUI. This approach has a theoretical advantage of less obstruction and postoperative voiding dysfunction, as well as avoiding some of the complications, such as bladder perforation and bowel perforation. Subsequently, deTayrac reported a 1 -year cure rate of $84 \%$ with the TOT procedure. ${ }^{6}$ We report on the objective and subjective outcomes of TOT after 24 months follow-up.

\section{Methods}

All female patients with SUI undergoing TOT from December 2004 to January 2006 were prospectively evaluated. The procedure was done under general or regional anesthesia. All patients were required to have a minimal follow-up of 24 months.

Patients with urge incontinence or pure intrinsic sphincter deficiency were excluded. All patients were evaluated with history including the number of pads used per day, physical examination including pelvic examination, urinalysis, urogenital distress inventory (UDI-6), analog global satisfaction scale (GSS), pad weight test, urodynamic studies included filling cystometry and Valsalva leak point pressure (VLPP) test. The VLPP was recorded via an 8-French urethral catheter, and both Valsalva maneuver and coughing were used to provoke SUI. The intravesical pressure (Pves) was used to calculate the VLPP starting at $250 \mathrm{~mL}$ bladder volume and subsequent increments of $50 \mathrm{~mL}$ until SUI was demonstrated or perceived by the patient. The history of SUI or the demonstration of SUI during physical examination or urodynamic studies constituted an indication for the TOT procedure.

We defined the cure of SUI as the disappearance of subjective and objective SUI using UDI-6 and urodynamic study after 12 months and negative cough test on physical examination after 24 months. Improvement of SUI was objectively defined as a decrease in leakage using the pad weight test and subjectively as a decrease in the UDI-6 score.

The transobturator approach was performed as described by Delorme in 2001 using a helical tunneler from the outside entrance point to adjust the tape without any tension. ${ }^{6}$ Cystoscopy was performed during the procedures in all patients and the catheter removed in the recovery room before the patients were discharged.

\begin{tabular}{lcrc}
\hline \multicolumn{4}{c}{ Table 1. Objective cure rate after 1 year and 2 years } \\
\hline & Cured & Improved & Failed \\
\hline After 1 year & $44 / 52(85 \%)$ & $4 / 52(7 \%)$ & $2 / 52(4 \%)$ \\
After 2 years & $42 / 52(80 \%)$ & $3 / 52(5 \%)$ & $2 / 52(4 \%)$ \\
\hline
\end{tabular}

\section{Statistical analysis}

We used the Wilcoxon matched pair test to compare between preoperative and postoperative symptoms, quality of life, maximum flow and post-void residual volumes. A value was considered statistically significant at $p<0.05$.

\section{Results}

A total of 52 consecutive patients fulfilled the inclusion criteria. The mean age was 50 (range 37 to 72 ) and the minimal follow-up was 24 months. Two patients were lost to follow-up after 12 months and 3 patients did not come for the 24-month evaluation.

The mean operative time was 18 minutes \pm 4 minutes (range 15 to 31 minutes) with an average amount of bleeding $57 \mathrm{cc} \pm 22 \mathrm{cc}$. The mean abdominal leak point pressure was $71 \mathrm{~cm} \pm 9 \mathrm{~cm} \mathrm{H}_{2} \mathrm{O}$ with no statistical significant differences between failures and cured/improved patients.

Our objective assessment demonstrated a $92 \%$ cure or improvement rate after 12 months and $85 \%$ after 24 months $(p<0.05)$ (Table 1). However, the subjective assessment using the UDI-6 demonstrated an $88 \%$ cure or improvement rate after 12 months and a $76 \%$ rate after 24 months $(p<0.05)$ (Table 2).

Denovo urgency developed in 4 patients $(8 \%)$, yet it disappeared spontaneously after 2 months in every patient, except for 1 patient despite the use of anticholinergic medications. This patient, however, improved significantly after the surgical release of the tape. Lateral vaginal injury was encountered in 1 patient, which was identified at the time of the injury and the tunneler was removed and correctly reinserted without further consequence. A urinary tract infection occurred in 3 patients and was managed with oral antibiotics. Two patients developed transient urinary retention after the removal of the catheter in the recovery room; the next day both patients experienced successful voiding. None of our patients developed erosion, nor did they experience bladder or urethral injury. The global satisfaction rate was 79\% (Table 3).

There was a slight decrease in early postoperative maximum flow rates; however, no significant differences were seen in maximum flow or residual post-void volumes when we compared preoperative values with those at 6 months, 12 months and 24 months (Table 4).

\begin{tabular}{lccc}
\hline \multicolumn{4}{l}{ Table 2. Subjective cure rate after 1 year and 2 years } \\
\hline & Cured & Improved & No changes \\
\hline After 1 year & $36 / 52(70 \%)$ & $9 / 52(18 \%)$ & $5 / 52(12 \%)$ \\
After 2 years & $34 / 52(65 \%)$ & $7 / 52(11 \%)$ & $6 / 52(13 \%)$
\end{tabular}

Subjective cure rate is urogenital distress inventory-6 (UDI-6). 
Table 3. Complications incurred with the transobturator vaginal tape

\begin{tabular}{ll}
\hline $\mathbf{N}(\%)$ & Perioperative and postoperative complication \\
\hline $0 \%$ & Bladder injury \\
$1(1 \%)$ & Lateral vaginal injury \\
$0 \%$ & Urethral injury \\
$0 \%$ & Vaginal erosion \\
$3(5 \%)$ & Urinary tract infection \\
$4(8 \%)$ & Denovo urgency \\
$2(4 \%)$ & Transient retention \\
\hline
\end{tabular}

\section{Discussion}

Although it is effective and easy to perform, the retropubic placement of suburethral tension-free vaginal tape has been associated with a number of perioperative and postoperative complications, including bowel, vascular and bladder injuries. $4,5,8,9$ This reality encouraged urologists to adopt the TOT method which relies on similar principles in treating SUI but with minimal morbidity.

In our series, we treated patients with pure stress incontinence with hypermobility and excluded patients with intrinsic sphincter deficiency without hypermobility. None of our patients had mixed or urge incontinence. So far none of the patients developed erosion, which is likely due to the use of the non-woven polypropylene mono filament with macropores. This material allows for good fibroblasts colonization of the tape, which is essential in preventing erosion and local infection.

We performed a cystoscopic examination in all of our patients to assess the urethra and bladder. No injury was identified. After performing 390 cases of TOT by different routes, Abdel-Fattah and colleagues found that lower urinary tract injury only occurred with the outside-in technique. ${ }^{10}$ Bladder injuries occurred in women who underwent concomitant vaginal surgery, while urethral injuries occurred in women undergoing secondary procedures ${ }^{10}$ In a recent literature review by Sivanesan and colleagues, several cases of bladder injury were reported; they recommend cystoscopy in cases of associated pelvic surgery or presence of prolapse, previous retropubic surgery or in cases where it is difficult to insert the tapes. ${ }^{11}$ In our practice we are considering abandoning the cystoscopic examination, except in cases of pelvic prolapsed. This change will result in shorter operative time and lower procedure cost.

The overall objective and subjective cure rates were different in our study population. This result could be due to the fact that frequency or urge incontinence is not demonstrated on the stress test, however it is reported by the patient using UDI-6 questionnaire.

Although urine retention and voiding dysfunction are thought to be less common after the transobturator approach, the rates vary from $0 \%$ to $15.6 \% .^{12}$ In our series, $8 \%$ of patients developed denovo urgency. No patients developed urinary retention, except transient retention that was relieved in a day. Unrecognized, vaginal laceration may predispose patients to mesh extrusion. We encountered 1 case of vaginal wall injury during the passage of the tunneler and it was reinserted again without any sequel. Therefore, it is highly recommended to inspect the lateral vaginal wall after passing the needle through transobturator foramen. ${ }^{13}$

The most important step to avoid erosion and voiding dysfunction was found to be tape adjustment without any tension or any contact with the urethra. ${ }^{14}$

We did not have any complaints of thigh pain in our series, which confirms recent findings of a meta-analysis that the outside-in technique is usually not associated with thigh pain. ${ }^{15}$

The subjective global satisfaction rate recorded at 12 months is $79 \%$. As is often the case, the rate of our subjective assessment is lower than the one observed during the objective clinical examination. ${ }^{16}$

\section{Conclusion}

The transobturator approach (from outside to inside) is an effective treatment of SUI with low morbidity. Thus far, we have enough data to support the use of the transobturator approach as a good alternative to the retropubic access. However, longer follow-up in larger populations should assess the long-term reliability of this procedure.

From the King Faisal Specialist Hospital and Research Centre, Alfaisal University, Riyadh, Saudi Arabia, and King Khalid University Hospital, King Saud University, Riyadh, Saudi Arabia

Table 4. Comparison of preoperative, 6 months, 12 months, 24 months postoperative uroflowmetry

\begin{tabular}{|c|c|c|c|c|c|}
\hline & Preoperative, $n=52$ & 6 months, $n=52$ & 12 months, $n=50$ & 24 months, $n=47$ & $\boldsymbol{p}$ \\
\hline Voided volume $(\mathrm{mL})$ & $299 \pm 52 \mathrm{cc}$ & $281 \pm 32 \mathrm{cc}$ & $263 \pm 46 \mathrm{cc}$ & $266 \pm 21 \mathrm{cc}$ & NS \\
\hline Maximum flow rate $(\mathrm{mL} / \mathrm{s})$ & $25 \pm 3 \mathrm{cc} / \mathrm{sec}$ & $23.5 \pm 1.6 \mathrm{cc} / \mathrm{sec}$ & $23 \pm 2 \mathrm{cc} / \mathrm{sec}$ & $24 \pm 3 \mathrm{cc} / \mathrm{sec}$ & NS \\
\hline Post-void residual & $18 \pm 15 \mathrm{cc}$ & $25 \pm 18 \mathrm{cc}$ & $16 \pm 13 \mathrm{cc}$ & $18 \pm 4 \mathrm{cc}$ & NS \\
\hline
\end{tabular}


$\mathrm{Al}$ Taweel and Rabah

Competing interests: None declared.

This paper has been peer-reviewed.

\section{References}

1. Abrams $P$, Cardozo L, Fall M, et al. The standardisation of terminology of lower urinary tract function: report from the Standardisation Sub-committee of the International Continence Society. Am J Obstet Gynecol 2002;187:116-26.

2. Ulmsten U, Petros P. Intravaginal slingplasty (IVS): an ambulatory surgical procedure for treatment of female urinary incontinence. Scand I Urol Nephrol 1995;29:75-82.

3. Karram M, Segal L, Vassallo J, et al. Complications and unwanted effects of the tension-free vaginal tape procedure. Obstet Gynecol 2003:101:929-32.

4. Bafghi A, lannelli A, Trastour $C$, et al. Bowel perforation as late complication of tension-free vaginal tape. J Gynecol Obstet Biol Reprod (Paris) 2005;34:606-7.

5. Hermieu JF, Messas A, Delmas V, et al. Bladder injury after TVT transobturator. Prog Urol 2003;13:115-7.

6. Delorme E. Transobturator urethral suspension: mini-invasive procedure in the treatment of stress urinary incontinence in women. Prog Urol 2001;11:1306-13.

7. deTayrac $R$, Deffieux $X$, Droupy $S$, et al. A prospective randomized trial comparing tension-free vaginal tape and transobturator suburethral tape for surgical treatment of stress urinary incontinence. Am J Obstet Gynecol 2004;190:602-8.
8. Peyrat L, Boutin JM, Bruyere $F$, et al. Intestinal perforation as a complication of tension-free vaginal tape procedure for urinary incontinence. Eur Urol 2001;39:603-5.

9. Nilsson CG, Falconer C, Rezapour M. Seven-year follow-up of the tension-free vaginal tape procedure for treatment of urinary incontinence. Obstet Gynecol 2004;104:1259-62.

10. Abdel-Fattah M, Ramsay I, Pringle $S$. Lower urinary tract injuries after transobturator tape insertion by different routes: a large retrospective study. BJOG 2006;113:1377-81.

11. Sivanesan $K$, Sathiyathasan $S$, Ghani R. Transobturator tension free vaginal tapes and bladder injury. Arch Gynecol Obstet 2009;279:5-7.

12. Fischer A, Fink T, Zachmann S, et al. Comparison of retropubic and outside-in transobturator sling systems for the cure of female genuine stress urinary incontinence. Eur Urol 2005;48:799-804.

13. David-Montefiore E, Frobert JL, Grisard-Anaf $M$, et al. Peri-operative complications and pain after the suburethral sling procedure for urinary stress incontinence: a French prospective randomised multicentre study comparing the retropubic and transobturator routes. Eur Urol 2006;49:133-8.

14. Boldelsson $G$, Henriksson L, Osser $S$, et al. Short term complications of the tension free vaginal tape operation for stress urinary incontinence in women. BJOG 2002;109:566-8.

15. Latthe $P$, Foon R, Toozs-Hobson P. Transobturator and retropubic tape procedures in stress urinary incontinence: a systematic review and meta-analysis of effectiveness and complications. BJOG 2007;114:522-31.

16. Deval B, Ferchaux J, Berry R, et al. Objective and Subjective Cure Rates after Trans-Obturator Tape Treatment of Female Urinary Incontinence. Eur Urol 2006;49:373-7.

Correspondence: Dr. Waleed Al Taweel, Assistant Professor\& Consultant urologist, Residency Program Director, Department of Urology, King Faisal Specialist Hospital \& Research Centre, Alfaisal University, PO Box 3354, Riyadh 11211, Saudi Arabia; fax: +966 1442 4301; drwt1@hotmail.com 